\title{
LA ELECCIÓN BRASILEÑA DE 2018: NUEVOS PATRONES DE FINANCIACIÓN, DESAFECCIÓN POLÍTICA Y REDES SOCIALES
}

The 2018 Brazilian Election: New Financing Patterns, Political Disaffection and Social Networks

Eleições brasileiras de 2018: novos padrões de financiamento, desafeição política e redes sociais

\section{Silvana KRAUSE a , Bruno MARQUES SCHAEFER ${ }^{\text {b }}$, Tiago Alexandre} LEME BARBOSA $^{c}$, Carolina PIMENTEL CORRÊA d ${ }^{\text {y Helcimara TELLES }}{ }^{\mathrm{e}}$

a Universidad Federal de Rio Grande do Sul. Porto Alegre, Brasil.

Email: silvana.krause@ufrgs.br. (D)

b Universidad Federal de Rio Grande do Sul. Porto Alegre, Brasil.

Email: bruno.schaefer@ufrgs.br. (D)

c Universidad Federal de Rio Grande do Sul. Porto Alegre, Brasil.

Email: tiago.leme@ufrgs.br. (1D)

d Universidad Federal de Rio Grande do Sul. Porto Alegre, Brasil.

Email: carolina.pimentel@ufrgs.br. (D)

e Universidad Federal de Minas Gerais. Belo Horizonte, Brasil. Email: maratelles@ufmg.br. (D)

Envío: 2019-08-26

Aceptado: 2020-03-03

First View: 2020-05-14

Publicado: 2020-05-30 


\section{Palabras clave: financiación electoral; elecciones; reglas electorales; comunicación política; anti-política}

\section{Resumen}

El documento analiza el patrón de financiación electoral de las elecciones presidenciales de 2010 a 2018 en Brasil. Sobre la base de datos del Tribunal Superior Electoral, se analizan los ingresos de los partidos y los candidatos presidenciales del período. Nuestros datos muestran que las elecciones de 2018 presentan un nuevo patrón de financiación que se explica por los cambios en la legislación electoral del país. Hasta 2018, las fuentes de financiación eran de corporaciones, pero en 2018 tenemos una competencia en la cual las partes dependen de los recursos de dinero público o de las donaciones de individuos. Nuestros hallazgos también indican que para 2018 hubo una coincidencia entre la cantidad de recursos del candidato y la cantidad de votos recibidos. En la última elección presidencial, este patrón varía, el candidato victorioso fue uno de los que más obtuvieron ingresos, lo que muestra un cambio en la competencia política del país.

\section{Abstract}

The article analyzes electoral financing patterns in the presidential elections from 2010 to 2018 in Brazil. Based on data from the Superior Electoral Court, party and presidential candidate income are analyzed. Our data show that the 2018 elections present a new financing pattern that is explained by the changes in the country's electoral legislation. Until 2018, the sources of financing came from corporations, but in 2018 we have a contest in which the parties depend on public resources or donations from individuals. Our findings also indicate that for 2018 there was a coincidence between the amount of candidate's resources and the number of votes received. In the last presidential election, this pattern changed, the victorious candidate was the one with the highest earnings, which shows a change in the country's political competition.
Palavras-chave:

financiamento eleitoral; eleições; regras eleitorais; comunicação política; antipolítica

\section{Resumo}

O artigo analisa o padrão de financiamento eleitoral das eleições presidenciais de 2010 a 2018 no Brasil. Com base nos dados do Tribunal Superior Eleitoral, são analisados os rendimentos dos partidos e dos candidatos à presidência do período. Nossos dados mostram que as eleições de 2018 apresentam um novo padrão de financiamento explicado pelas mudanças na legislação eleitoral do país. Até 2018, as fontes de financiamento eram de empresas, mas em 2018 temos uma competição em que as partes dependem de recursos públicos ou doações de indivíduos. Nossas descobertas também indicam que em 2018 houve uma coincidência entre a quantidade de recursos do candidato e o número de votos recebidos. Na última eleição presidencial, esse padrão mudou, o candidato vitorioso foi um daqueles com maiores recursos, o que mostra uma mudança na competição política do país. 


\section{INTRODUCCIÓN ${ }^{1}$}

Las elecciones brasileñas de 2018 han sorprendido a muchos analistas políticos. Explicar la victoria de un candidato presidencial populista y de extrema derecha, miembro de un pequeño partido como el Partido Social Liberal (PSL), continúa representando un desafío para los politólogos. Con el éxito de Jair Bolsonaro, Brasil se ha situado en el mapa de países que están vivenciando la emergencia de líderes con este perfil ideológico, como el ascenso de Erdogan en Turquía, Trump en los Estados Unidos o Viktor Orban en Hungría. A su vez, las elecciones proporcionales para el Poder Legislativo también han experimentado cambios importantes, llegando a ser las más fragmentadas de su historia: 30 partidos han obtenido escaños en la Cámara de los Diputados y el número efectivo de partidos (Laakso y Taagepera, 1979), se sitúa en 17. Además, el Partido de los Trabajadores (PT) pierde por primera vez desde 2002 las elecciones presidenciales. Estas elecciones también se han caracterizado por otras alteraciones como las nuevas reglas de financiación, la duración de la campaña electoral y las estrategias de comunicación. Las elecciones generales de 2018 han sido las primeras tras la prohibición de las donaciones de empresas. Con relación a las estrategias de comunicación, la televisión, hasta el momento el medio de comunicación con mayor impacto en la decisión de voto, parece haber sido sustituida por las redes sociales.

Ante este contexto, es importante presentar la legislación que reguló la financiación, el patrón de las donaciones y las redes de financiación de los candidatos presidenciales en elecciones anteriores, especialmente, en las elecciones de 2010 y 2014. El clima de polarización, inestabilidad y escándalos sobre corrupción sumado a un perfil de financiación altamente concentrado han desencadenado importantes alteraciones en la legislación sobre la financiación política y las campañas electorales. A continuación, se analizan las nuevas reglas para las elecciones de 2018 y destacamos las características que influenciaron la disputa presidencial: el rechazo a la clase política y la intensa utilización de las redes sociales durante la campaña. Finalmente, se presentan los datos sobre cómo la ruptura del patrón de financiación ha impactado en las elecciones de 2018 y en sus resultados. Se percibe que la modificación de las redes de financiación ha originado un escenario donde el dinero público es la principal fuente de recursos para partidos y candidatos. También han disminuido las prestaciones de cuentas de la campaña presidencial al Tribunal Electoral y han aumentado las denuncias de financiación irregular. Existen fuertes indicios de que muchas empresas han invertido en las redes sociales de apoyo del candidato vencedor. Por tanto, los cambios en las normas de financiación y de campaña electoral han impactado, sin duda, en algunos patrones, pero

1 Partes de este artículo aparecen publicadas en Zeitschrift für Parteienwissenchsften (Heft 1. 25 Jarhgang. 2019) del PRuF. 
no han enfrentado de forma eficaz el impacto del poder económico en la dinámica electoral.

\section{LA NUEVA DEMOCRACIA Y LA FINANCIACIÓN POLÍTICA ANTES DE LAS RECIENTES REFORMAS}

En Brasil, la regulación de la financiación política está caracterizada por los cambios de reglas debido, fundamentalmente, a dos razones: las constantes alteraciones de régimen político y la tradicional fragilidad de los partidos políticos. A lo largo de las diferentes fases de la competición política brasileña, desde el Imperio hasta la nueva democracia, se han creado códigos y leyes con la intención de regular la financiación de los partidos. En el periodo que analizamos, caracterizado como la nueva democracia e instalado en 1985, la financiación política también ha enfrentado diversos cambios en sus reglas. Una de las principales razones de esta inestabilidad son los escándalos sobre las relaciones entre la política y el poder económico en el país, uno de los mayores desafíos para la democracia brasileña. En la nueva democracia, Brasil se ha caracterizado por campañas electorales carísimas, alcanzando valores comparables con los de las elecciones presidenciales de los Estados Unidos (Samuels, 2001). Las campañas caras limitan la concurrencia y restringen el acceso a la política, especialmente en contextos con una fuerte desigualdad social y una economía poco competitiva y concentradora. El aumento del gasto en campaña ha ascendido vertiginosamente desde la década de 1990. Mientras que en el 2002 se gastaron cerca de 150 millones de reales ${ }^{2}$, en 2014 se superaban los 800 millones de reales ${ }^{3}$.

Las campañas en Brasil son caras debido a diferentes factores. Primero, el sistema electoral de lista abierta para el Poder Legislativo coloca el foco en el candidato, por lo que durante la campaña el candidato compite también con sus colegas de partido. La disputa es bastante ardua y los políticos necesitan buscar recursos económicos propios, independientemente de sus partidos. Existe una lucha interna fratricida entre los candidatos de un mismo partido. Los candidatos al Legislativo mantienen contacto directo con sus donantes y el partido no es fundamental para su campaña. La lista abierta estimula la búsqueda de financiadores y poseer una fuente propia de recursos para la campaña. Segundo, las campañas centradas en el perfil personal de un político demandan una programación televisiva con elevados costes de producción. El espacio televisivo es ofrecido de forma gratuita por ley,

2 Según la cotización de enero de 2020: en dólares más de 37 millones.

3 Los valores han sido ajustados a lo largo del texto conforme la inflación (IPCA - índice de Precios al consumidor). Es decir, se han ajustado de acuerdo con el valor referente a 2018. 
pero la calidad del programa depende de los recursos financieros del candidato y del partido. En un país con grandes distancias geográficas, la televisión y los spots son una herramienta fundamental para que los políticos se comuniquen con su electorado. En Brasil es conocida la fuerte influencia que la televisión ha ejercido en el votante indeciso. Otro factor importante que contribuye al aumento de los costes de las campañas son los gastos con consultores y especialistas en marketing. Además, la cultura antipartidista del país supone que el éxito electoral del candidato dependa de las relaciones personales y de su capacidad para generar apoyo electoral personal. Es importante destacar que la dinámica partidista del país cuenta con una tradición enraizada e influenciada por el Estado (Fleischer, 1997) con un papel preponderante en la creación y el formato de los partidos políticos (Souza, 1976). Las listas de los partidos brasileños presentan, tanto en su origen como en su desarrollo organizacional, vínculos originariamente frágiles con grupos y clivajes sociales ${ }^{4}$, así como su estructuración deriva de experiencias anteriores al periodo autoritario.

En 1989, la primera elección presidencial directa, aprobada por la nueva Constitución de 1988 y marcada por una contienda electoral competitiva, aún no permitía, por ley, las donaciones de empresas. Aun así, tuvieron lugar varios escándalos relacionando políticos y empresarios. Fernando Collor de Melo, primer presidente electo de la nueva democracia, renunció en 1992 antes de ser sometido a un impeachment, tras una serie de denuncias que apuntaban irregularidades en la financiación de su campaña. Este escándalo desencadenó la creación de una legislación sobre financiación electoral. La primera reacción (Krause, Rebello y Da Silva, 2015, p. 255) fue la creación de una ley temporal (Ley $n^{\circ} 8.713 / 1993$ ) para regular la elección presidencial de 1994. Esta establecía de forma clara cómo los partidos debían administrar sus finanzas durante las campañas y cómo podían utilizar los recursos provenientes de las empresas privadas, las donaciones personales y del fondo partidista.

En 1995 se aprobó la Ley de los Partidos Políticos, n 9096, y en 1997, la Ley de las Elecciones, $n^{\circ}$ 9504. La legislación de 1995 reglamentaba el artículo $n^{\circ} 17$ de la Constitución Federal de 1988, que preveía mayor libertad organizacional para los partidos. La Ley de los Partidos establecía los criterios para la fundación y la financiación de éstos, alterando aspectos importantes de la legislación en vigor desde el régimen civil-militar. Las direcciones nacionales, destinatarias de los recursos públicos provenientes del Fondo Partidista, pasaron a no tener ninguna obligación legal de traspasar este dinero a sus instancias inferiores, es decir, estaduales y municipales. Esto generó una concentración de recursos en las direcciones nacionales de las los partidos y una mayor centralización de las organizaciones partidistas. La

4 A excepción del PT que nació y se impulsó en el seno del movimiento sindical de los años 1980. 
distribución del Fondo Partidista depende de dos criterios: ecuanimidad y proporcionalidad. El 5\% del total de los recursos son distribuidos a todos los partidos y el resto según el número de representantes en la Cámara de los Diputados en la legislatura anterior.

La Ley de Elecciones limitaba las donaciones empresariales (persona jurídica) al $2 \%$ de la facturación bruta de la empresa y las de los ciudadanos (persona física) al $10 \%$ para campaña. Como los límites establecidos son porcentajes y no valores, grupos empresariales y personas físicas con altos lucros conseguían financiar cuantías superiores, adquiriendo un poder de influencia importante en el proceso político. También debe tenerse en cuenta que en Brasil es común que un grupo económico esté formado por diversas personas físicas, aumentando su capacidad de financiación. En el caso de las donaciones por parte de personas físicas es común la utilización del nombre de parientes y amigos para aumentar las donaciones de campaña. Otro aspecto importante es que no existía un limite de gasto para campaña, cada candidato decidía cuánto gastar, siempre y cuando justificase el origen de dichos recursos y respetasen la legislación mencionada (Krause, 2010). Por otro lado, hay que resaltar que empresas y personas físicas pueden financiar, al mismo tiempo, diferentes partidos y candidatos. Un ejemplo de esta práctica fue el escándalo en la elección de 2014, cuando en un testimonio a la justicia se relató como una importante empresa brasileña financió a 1.824 candidatos de 19 partidos, de los cuales 167 resultaron elegidos como diputados federales.

\section{LA DINÁMICA DE LAS DONACIONES DE 2010 Y 2014}

Al analizar el total de recursos presentados en las elecciones presidenciales antes de las de 2018, impresiona el grado de concentración y centralización de las donaciones en tres dimensiones: a) concentración de un tipo de financiador, el escaso peso de la financiación pública y las donaciones de personas físicas; b) la mayor parte de la financiación proviene de un pequeño grupo de empresas; c) la mayor parte de las donaciones se dirigen a unos pocos candidatos, a pesar de la amplia oferta de candidaturas.

Conforme puede observarse en la tabla 1, las campañas presidenciales de 2010 y 2014 fueron financiadas, prácticamente en exclusiva, por donaciones proveniente de personas jurídicas (empresas). En 2010 el 95,47\% de los recursos de todas las campañas provenían de empresas, mientras que en 2014 alcanzaba el 97,5\%. En términos nominales, en 2010 el valor aproximado gira en torno a 445 millones de reales ${ }^{5}$ y en 2014 cerca de 780 millones.

5 En dólares, los valores son 109 y 192 millones, respectivamente. 
KRAUSE ETAL.

LA ELECCIÓN BRASILEÑA DE 2018: NUEVOS PATRONES DE FINANCIACIÓN...

Tabla 1. Origen de las donaciones de las campañas presidenciales \% (2010-2014)

\begin{tabular}{lcc}
\hline \multicolumn{1}{c}{ Año/Tipo de eecurso } & $\mathbf{2 0 1 0}$ & $\mathbf{2 0 1 4}$ \\
\hline Dinero público & 0,69 & 0,90 \\
Persona física & 3,82 & 1,60 \\
Recursos propios & 0,02 & 0,01 \\
Persona jurídica & 95,47 & 97,50 \\
\hline
\end{tabular}

Fuente: TSE 6 .

Del total del valor correspondiente a 2010, el $81,4 \%$ fue donado directamente a las campañas presidenciales y sus respectivos comités financieros, el resto fue donado a las Ejecutivas Nacionales que posteriormente lo transfirieron a las campañas. En 2014, el 78,9\% fue donado directamente a las campañas presidenciales. Por tanto, los vínculos entre empresas y candidatos se establecen de forma directa en la disputa presidencial.

Otro aspecto que debe ser observado es que las donaciones provienen de pocas empresas. En 2010, los 20 principales financiadores de campaña donaron casi la mitad del total, el 49,53\%. Ya en 2014, este valor aumentó, situándose en un $67,02 \%$. De acuerdo con el TSE, los sectores y las empresas son las mismas. Las principales empresas financiadoras de las campañas presidenciales provienen del sector alimenticio, como la JBS S/A y Cutrale; de la construcción civil, como Andrade Gutiérrez, Multiplan, UTC Engenharia y OAS; bancos privados, como ITAU y BTG Pactual'. Llama la atención que las empresas del sector alimenticio dependen bastante de la financiación pública del Gobierno Federal, otorgado a partir de bancos de desarrollo como el BNDES (Banco Nacional de Desarrollo Económico y Social). Mientras que el sector de la construcción civil fue beneficiado durante este periodo por la financiación pública y la demanda gubernamental por obras para recibir la Copa del Mundo y las Olimpíadas. Estas empresas también se han beneficiado de la inversión gubernamental en infraestructura y vivienda de protección oficial. Sin embargo, es interesante destacar que, conforme apunta Carazza (2018), estos sectores no son los mayores contribuidores del PIB nacional. Sectores como el agronegocio, a pesar de ser uno de los sectores más importantes de la economía nacional, parecen influenciar la política a partir de otras acciones.

6 El Tribunal Superior Electoral (TSE) es un organismo federal de justicia electoral en Brasil. Responsable de la organización, implementación e inspección del proceso electoral, así como del registro, control contable y rendición de cuentas de los partidos.

7 Muchas de ellas directamente implicadas con escándalos de corrupción, especialmente las del ramo de la construcción civil y las del alimenticio. 
En relación con los principales destinarios de estas donaciones, tanto en 2010 como en 2014, los mayores beneficiados fueron los dos candidatos principales. La candidata del PT, Dilma Rousseff, en ambas elecciones; José Serra, en 2010, y Aécio Neves, en 2014, ambos del Partido de la Social Democracia Brasileña (PSDB). Marina Silva, la tercera candidata más votada en 2010 (PV) y en 2014 (PSB) también fue la tercera en recibimiento de donaciones. En la tabla 2 se presenta el total recaudado por todos los candidatos según los datos del Tribunal Superior Electoral. Los valores están en porcentajes considerando el total recolectado por todos los candidatos en la elección.

En 2010, el PT recaudó más del 50\% del total de las donaciones a la campaña presidencial, proveniente la mayor parte de donaciones empresariales $(49,98 \%$ del total recaudado en la campaña). En 2014, Aécio Neves fue el mayor recaudador. Dado que las empresas son los principales donantes, los candidatos que más dinero recaudaron también son quienes recibieron más donaciones privadas.

Los partidos políticos se han desvinculado de identidades ideológicas fijas y han ampliado su abanico de conexiones: tanto en términos del electorado (banderas más genéricas y vínculos sociales más inestables), como, en términos de financiación, adoptando estrategias catch-all (Kirchheimer, 1966). Los mayores donadores de campaña tendieron a comportarse como inversores, distribuyendo los valores según las posibilidades de victoria de los candidatos. El Partido de Lula (PT), tradicionalmente resistente a recibir financiación empresarial, flexibilizó a partir de 1990 su posición aceptando donaciones empresariales (Hunter, 2007).

En las figuras 1 y 2 , observamos qué empresas donaron para qué candidatos y se verifica la existencia de donaciones simultáneas, creándose un lazo cuando se establecen vínculos simultáneos. En la figura 1 se presentan los datos de la red de financiaciones de 2010. Como se puede observar, los candidatos del PT, del PSDB, del PV (Partido Verde) y del PRTB (Partido Renovador Trabajador Brasileño) están relacionados. El número expuesto se corresponde con el total de donaciones simultáneas. PT y PSDB, los principales competidores del 2010 poseen 153 lazos. Es decir, los candidatos de sendos partidos recibieron 153 donaciones empresariales procedentes de las mismas corporaciones. La empresa JBS S/A ilustra esta tendencia. La empresa realizó dos donaciones al candidato José Serra del PSDB y cinco a Dilma Rousseff, candidata del PT. En el caso del PSDB fueron 2.475 .000 reales y en el del PT 2.970.000 ${ }^{8}$. Partidos menores como el PSDC, el PSOL, el PSTU, el PCB y el PCO han recibido donaciones empresariales en exclusiva, por lo que no forman parte de esta red.

8611.000 dólares y 733.000 dólares respectivamente. 
KRAUSE ETAL.

LA ELECCIÓN BRASILEÑA DE 2018: NUEVOS PATRONES DE FINANCIACIÓN...

Tabla 2. Recaudación de los candidatos

\begin{tabular}{|c|c|c|c|c|c|}
\hline Año & Partido & $\begin{array}{l}\text { Dinero } \\
\text { público }\end{array}$ & $\begin{array}{l}\text { Persona } \\
\text { física }\end{array}$ & $\begin{array}{l}\text { Recursos propios } \\
\text { candidato }\end{array}$ & $\begin{array}{l}\text { Persona } \\
\text { jurídica }\end{array}$ \\
\hline \multirow{9}{*}{2010} & PCB & 0,00 & 0,00 & 0,00 & 0,00 \\
\hline & PCO & 0,00 & 0,00 & 0,00 & 0,00 \\
\hline & PRTB & 0,00 & 0,00 & 0,00 & 0,02 \\
\hline & PSDB & 0,58 & 0,47 & 0,00 & 39,01 \\
\hline & PSDC & 0,01 & 0,00 & 0,00 & 0,12 \\
\hline & PSOL & 0,01 & 0,01 & 0,01 & 0,02 \\
\hline & PSTU & 0,00 & 0,02 & 0,00 & 0,01 \\
\hline & PT & 0,00 & 0,57 & 0,00 & 49,98 \\
\hline & PV & 0,00 & 2,71 & 0,00 & 6,38 \\
\hline \multirow{11}{*}{2014} & PCB & 0,01 & 0,00 & 0,00 & 0,00 \\
\hline & PCO & 0,00 & 0,00 & 0,00 & 0,00 \\
\hline & PRTB & 0,01 & 0,00 & 0,00 & 0,04 \\
\hline & PSB & 0,00 & 0,59 & 0,00 & 12,88 \\
\hline & PSC & 0,00 & 0,00 & 0,00 & 0,15 \\
\hline & PSDB & 0,02 & 0,87 & 0,00 & 45,99 \\
\hline & PSDC & 0,00 & 0,00 & 0,00 & 0,04 \\
\hline & PSOL & 0,03 & 0,01 & 0,00 & 0,01 \\
\hline & PSTU & 0,01 & 0,01 & 0,00 & 0,00 \\
\hline & PT & 0,00 & 0,10 & 0,00 & 38,37 \\
\hline & PV & 0,86 & 0,00 & 0,00 & 0,00 \\
\hline
\end{tabular}

Fuente: TSE. 
Figura 1. Red de financiación electoral de los partidos políticos brasileños (2010)

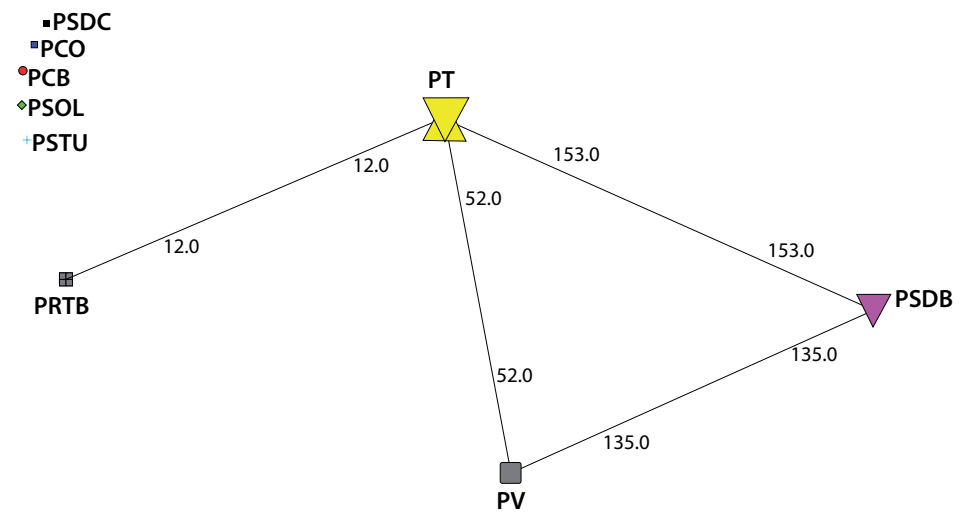

Fuente: TSE (Tribunal Superior Electoral).

En la elección de 2014, la red de financiación es aún más densa. Existe una concentración mayor de recursos (menos donadores) y una dispersión mayor: esos mismos donantes realizaron donaciones para un número mayor de candidatos. Los lazos entre el PT y el PSDB pasan de 35 mil. La propia JBS S/A aumentó exponencialmente su contribución para campaña. Realizaron 7 donaciones al PRTB de Levy Fidelix, 31 donaciones al PSB de Marina Silva, 441 al PSDB de Aécio Neves y 76 al PT de Dilma Rousseff. Los valores nominales son, respectivamente: $\mathrm{R} \$$ $123.000,00^{9} ; \mathrm{R} \$ 6.150 .000,00 ; \mathrm{R} \$ 49.820 .000,00$ y $\mathrm{R} \$ 67.035 .000,00$.

Figura 2. Red de financiación electoral de los partidos políticos brasileños (2014)

口PV

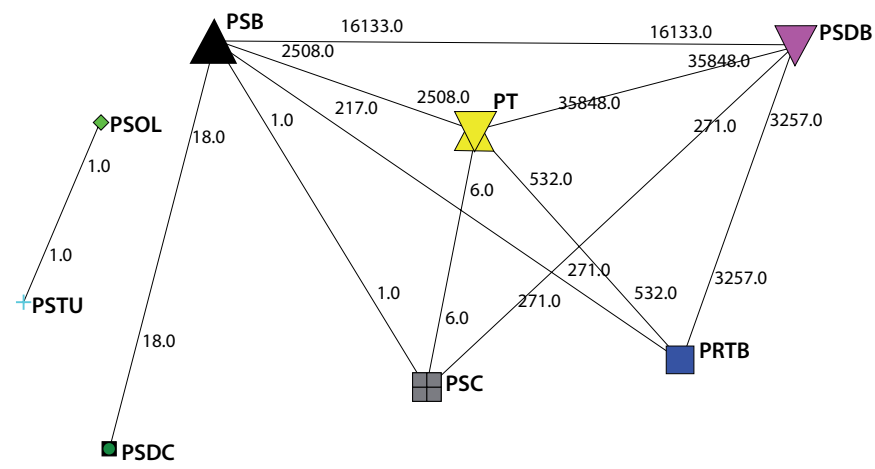

Fuente: TSE.

9 En dólares: 29.341,53; 1.467.067,35; 11.884.511,18; 15.991.132,21, respectivamente. 


\section{EL ESCENARIO PREVIO A LA ELECCIÓN: POLARIZACIÓN, INESTABILIDAD POLÍTICA Y LA OPERACIÓN LAVA JATO}

Desde 1994, segunda elección directa para la presidencia de la República, el PSDB y el PT polarizaban la competición presidencial. En la siguiente tabla se observan los porcentajes de voto de ambos partidos. Rápidamente se identifica que todos los presidentes pertenecían a una de estas organizaciones y que cuando hubo segunda vuelta fue disputada por ambos hasta 2014.

Tabla 3. Evolución de la votación PT x PSDB elecciones presidenciales

\begin{tabular}{|c|c|c|c|c|c|}
\hline 1994 & 1998 & 2002 & 2006 & 2010 & 2014 \\
\hline $1^{\text {a }}$ vuelta & $1^{\text {a }}$ vuelta & $1^{a}$ vuelta & $1^{a}$ vuelta & $1^{a}$ vuelta & $1^{a}$ vuelta \\
\hline \multirow{3}{*}{$\begin{array}{l}\text { FHC (PSDB) } \\
=55,22 \%\end{array}$} & \multirow[b]{2}{*}{$\begin{array}{l}\text { FHC (PSDB) } \\
=53 \%\end{array}$} & $\begin{array}{l}\text { Serra (PSDB) } \\
=23 \%\end{array}$ & $\begin{array}{l}\text { Alckmim (PSDB) } \\
=41,6 \%\end{array}$ & $\begin{array}{l}\text { Serra (PSDB) } \\
=32 \%\end{array}$ & $\begin{array}{l}\text { Aécio (PSDB) } \\
=33,5 \%\end{array}$ \\
\hline & & $\begin{array}{l}\text { Lula (PT) } \\
=46 \%\end{array}$ & $\begin{array}{l}\text { Lula (PT) } \\
=48,6 \%\end{array}$ & $\begin{array}{l}\text { Dilma (PT) } \\
=46 \%\end{array}$ & $\begin{array}{l}\text { Dilma (PT) } \\
=41,5 \%\end{array}$ \\
\hline & \multirow{3}{*}{$\begin{array}{l}\text { Lula (PT) } \\
=31 \% \\
1^{\circ} \text { Turno }\end{array}$} & $2^{a}$ vuelta & $2^{\mathrm{a}}$ vuelta & $2^{a}$ vuelta & $2^{a}$ vuelta \\
\hline \multirow{2}{*}{$\begin{array}{l}\text { Lula (PT) } \\
=39,97 \%\end{array}$} & & $\begin{array}{l}\text { Serra (PSDB) } \\
=38 \%\end{array}$ & $\begin{array}{l}\text { Alckmin (PSDB) } \\
=39 \%\end{array}$ & $\begin{array}{l}\text { Serra (PSDB) } \\
=43 \%\end{array}$ & $\begin{array}{l}\text { Aécio (PSDB) } \\
=48,35 \%\end{array}$ \\
\hline & & $\begin{array}{l}\text { Lula (PT) } \\
=61 \%\end{array}$ & $\begin{array}{l}\text { Lula }(\mathrm{PT}) \\
=60 \%\end{array}$ & $\begin{array}{l}\text { Dilma }(\mathrm{PT}) \\
=56 \%\end{array}$ & $\begin{array}{l}\text { Dilma (PT) } \\
=51,65 \%\end{array}$ \\
\hline
\end{tabular}

Fuente: TSE.

Desde la elección de 2014 hasta la de 2018, que consagra la elección de Jair Bolsonaro, el país enfrentó procesos políticos turbulentos como un impeachment10, protestas sociales (Gohn, 2017) y operaciones de la policía federal con un alto impacto mediático que afectaron a las instituciones políticas. Al mismo tiempo, el país sufrió una crisis económica y constantes escándalos de corrupción ampliamente cubiertos por los medios de comunicación, ampliando la percepción de la corrupción y fragilizando la imagen de la presidenta reelegida y su partido (PT), de las empresas de construcción civil y el liderazgo de Lula (Silva, 2017). Así, la corrupción afectó negativamente a la confianza del electorado y facilitó que los diputados, en

10 De mayo a agosto de 2016, el país enfrentó un proceso de impeachment contra la presidenta, acusada de cometer delito de responsabilidad fiscal, además de la firma de decretos que generaron gastos sin la autorización del Congreso Nacional. 
nombre de los ciudadanos que protestaban en las calles, abandonasen el gobierno de coalición (Telles, 2016).

Paralelamente al proceso de destitución de la presidenta Dilma y desde 2014, la Policía Federal Brasileña estaba llevando a cabo diversas investigaciones inspiradas por la Operación Manos Limpias italiana y bautizada como Operación Lava Jato ${ }^{11}$. Esta operación investiga tanto crímenes de corrupción activos y pasivos como: gestiones y operaciones fraudulentas, lavado de dinero, organizaciones criminales, obstrucción de la justicia, prevaricación, cohecho y tráfico de influencias. Con base en diferentes investigaciones y los acuerdos por información con los investigados, la Operación Lava Jato registró la implicación de miembros administrativos de la empresa estatal petrolífera brasileña (Petrobrás), de políticos de diferentes partidos con cargos en el Ejecutivo y del Legislativo, y, de grandes empresarios del país (muchos de ellos grandes donadores de las campañas electorales).

La operación Lava Jato tuvo una amplia repercusión en los medios de comunicación y en la formación de la opinión pública. El juez Sergio Moro, responsable de las causas de esta operación en primera instancia, fue reconocido, por parte de la población, como un héroe brasileño al luchar contra la corrupción. Actualmente, Sergio Moro es ministro de Justicia y Seguridad Pública, tras aceptar la invitación del presidente Jair Bolsonaro. Por tanto, la operación Lava Jato ha tenido un papel determinante en el escenario político e histórico, incluso a pesar de que las sentencias de los casos englobados en la operación dividan opiniones en la esfera jurídica.

A partir del 2014 también toma forma un nuevo escenario político, los partidos tradicionales, y especialmente el PT, enfrentaron numerosas denuncias de corrupción, despertando un fuerte sentimiento de desconfianza y rechazo en los ciudadanos hacia los partidos. Este hecho abrió una puerta para el crecimiento de movimientos autodenominados como "antipartidistas» como, por ejemplo, el Movimiento Brasil Libre (MBL) y Sal a la Calle (Vem Pra Rua). Para Telles (2015) «las notician son producidas para ser consumidas y parece que ya existe un mercado político en el país que busca un portavoz de extrema derecha que simbolice el antipetismo» ${ }^{12}$, y la ascensión de Jair Bolsonaro hasta la presidencia confirman esta visión.

\section{LAS NUEVAS REGLAS PARA LA ELECCIÓN DE 2018}

Ante un escenario preelectoral de creciente polarización política, denuncias de corrupción relacionadas con empresas privadas y la Operación Lava Jato surgieron varias iniciativas para alterar las reglas sobre financiación de campaña. Estas

11 Lava coches.

12 Traducción libre. Antipetismo: votantes que rechazan el PT (Partido dos Trabalhadores). 
modificaciones pretendían desvincular a la clase política de las empresas financiadoras y limitar los gastos de campaña. En 2015, la Orden de Abogados de Brasil (OAB) formuló que las donaciones empresariales no se ajustaban a la Constitución y el Tribunal Supremo Federal (STF), finalmente, las sentenció como anticonstitucionales, quedando prohibidas. Las justificaciones de los ministros del STF giraban en torno a los problemas que suponen para el pluralismo político al beneficiar a algunos políticos en detrimento de otros. Luego, la Ley 13.165/2015 prohíbe que las empresas financien partidos políticos y candidatos. Además, un año antes de la elección de 2018 se limita el gasto de campaña (Ley 14288/2017). Para la campaña presidencial se establece como límite las siguientes cantidades: 70 millones de reales para la primera vuelta y 35 para la segunda.

A pesar de haberse estipulado un techo de gastos y prohibirse la financiación empresarial, estas medidas no han conseguido frenar la influencia del poder económico en la campaña. Esta nueva legislación ha generado un cambio en la forma de donar, es decir, los mayores donantes individuales han aumentado sus contribuciones al compararlas con las de elecciones anteriores. Miembros de una misma familia, pertenecientes al mismo grupo empresarial, y que nunca habían realizado una donación pasaron a registrar donaciones elevadas (Rebello y Martins, 2018). Por otro lado, si las grandes empresas vinculadas a los escándalos evitaron financiar campañas, algunos empresarios donaron altas cuantías a candidatos del Poder Legislativo. Lo que no excluía la posibilidad de que un mismo empresario donara para diferentes candidatos y competidores entre sí (Goulart, 2018).

Con la intención de tornar las campañas más baratas, también se disminuyó significativamente el tiempo de campaña electoral y propaganda en la televisión. De acuerdo con la nueva regla del artículo 240 del Código Electoral Brasileño, el tiempo de campaña fue reducido a 52 días antes de la primera vuelta y a 20 antes de la segunda. A su vez, el periodo de propaganda en la televisión y radio -más conocido como Horario Gratuito de Propaganda Electoral (HGPE)-, también fue reducido a 35 días antes de la primera vuelta y 15 días antes de la segunda. Con relación a los cambios publicitarios, también se disminuyó la aparición de los candidatos: antes de la primera vuelta, las radios y televisiones articulan dos bloques diarios de 25 minutos, y, antes de la segunda vuelta, dos bloques diarios de 10 minutos. Del mismo modo, los tipos de propaganda fueron bastante restringidos, prohibiendo, entre otros, efectos especiales, montajes y dibujos animados. Se prohibió la divulgación de jingles el día de la elección y se vetaron los muñecos hinchables y los outdoors electrónicos. La ley también restringió los tamaños de la propaganda en vehículos: los adhesivos no debían superar los $50 \mathrm{~cm} \times 50 \mathrm{~cm}$ y los tintados el tamaño del limpiaparabrisas trasero.

Hasta el formato de los debates y la propaganda permitida en Internet sufrieron modificaciones. Para exhibir debates con candidatos a cargos ejecutivos, las emisoras son obligadas a invitar a partidos con al menos 5 parlamentarios en 
el Congreso Nacional. Ya en Internet, los partidos y candidatos se pueden anunciar en las redes sociales mediante pago, pero el pago no puede ser realizado por donantes físicos. Además, se establece un desempeño electoral mínimo para que los partidos tengan derecho a tiempo de propaganda y al Fondo Partidista. Las limitaciones para propaganda pretendían reducir el impacto financiero en la campaña, reducir costes y generar mayor equidad entre los candidatos.

Otra alteración significativa ha sido la Ley n. ${ }^{\circ} 13847$ de 2017, que crea el denominado Fondo Especial de Financiación de Campañas (FEFC) y destina más de 1,7 billones de reales de dinero público a que los partidos políticos financien sus campañas y tengan derecho a tiempo de televisión y al presupuesto del Fondo Partidista ${ }^{13}$. Luego, los valores destinados a los partidos y candidatos en 2018 procedían del Presupuesto del Gobierno Federal (FEFC y Fondo Partidista), además de las donaciones individuales y los recursos propios. Conforme puede observarse en el gráfico 1, el dinero público destinado a estos ha crecido considerablemente desde 1994. Entre 2014 y 2015, este valor sobrepasa su duplicación, pasando de 308 millones de reales, a más de 811 millones $^{14}$. El vacío dejado por las empresas ha sido ocupado por el presupuesto federal. En la campaña de 2018, los valores del Fondo Partidista y del FEFC casi llegan a 2,5 billones de reales ${ }^{15}$.

\section{Gráfico 1. Dinero público (en millones de reales)}

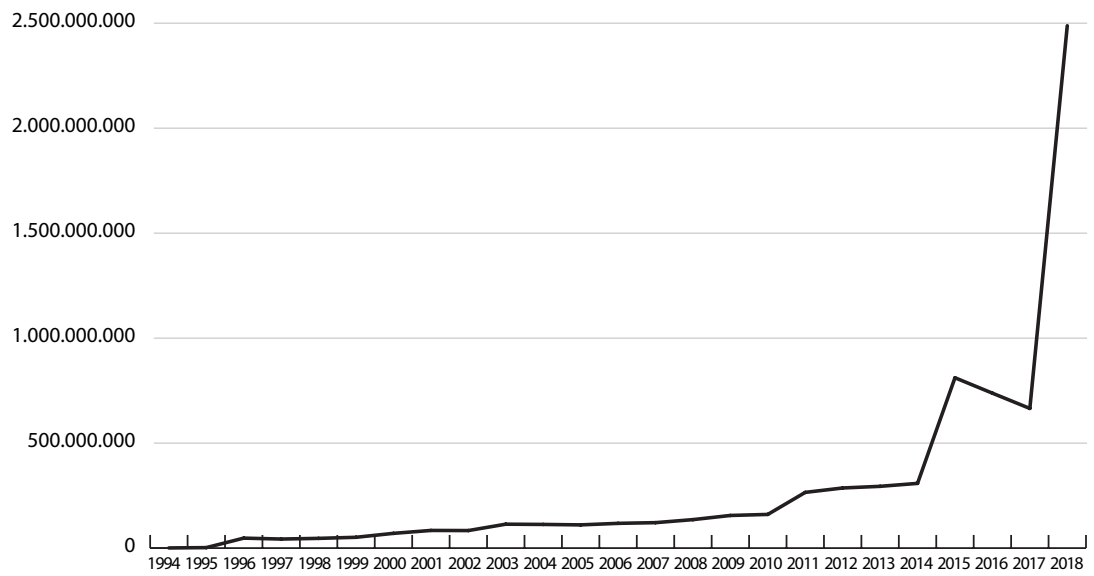

Fuente: TSE.

13 Es importante tener en cuenta que, si bien el Fondo del Partido se distribuye año tras año a los partidos, para mantener las organizaciones, el Fondo Electoral se distribuye cada dos años, para financiar campañas nacionales, estatales y municipales.

14 De cerca de 76 millones de dólares para 201 millones de dólares.

15 Valor en dólar: 617 millones (06.01.2020). 
Tabla 4. Reglas de Campaña en Brasil

\begin{tabular}{|c|c|c|}
\hline & Hasta 2018 & En 2018 \\
\hline $\begin{array}{l}\text { Financiación } \\
\text { (Donaciones) }\end{array}$ & $\begin{array}{l}\text { Donaciones de personas físicas, } \\
\text { recursos propios, dinero público } \\
\text { (Fondo Partidista), donaciones de } \\
\text { otros candidatos y donaciones de } \\
\text { personas jurídicas. Los criterios } \\
\text { para donaciones de personas } \\
\text { jurídicas son hasta un } 2 \% \text { de la } \\
\text { facturación bruta de la empresa. } \\
\text { Las donaciones de personas físicas } \\
\text { y del propio candidato (recursos } \\
\text { propios), se limitan al } 10 \% \text { del total } \\
\text { del rendimiento bruto de la persona, } \\
\text { de acuerdo con la declaración de la } \\
\text { renta. } \\
\text { Sin límite de gastos de campaña. }\end{array}$ & $\begin{array}{l}\text { Donaciones de personas físicas, } \\
\text { recursos propios y dinero público } \\
\text { (Fondo Partidista y Fondo } \\
\text { de Financiación Especial de } \\
\text { Campañas-FEFC), donaciones de } \\
\text { otros candidatos. Las donaciones } \\
\text { de personas físicas y del propio } \\
\text { candidato (recursos propios), } \\
\text { se limitan al 10\% del total del } \\
\text { rendimiento bruto de la persona, } \\
\text { de acuerdo con la declaración de } \\
\text { la renta. } \\
\text { El } 30 \% \text { del valor del FEFC debe } \\
\text { ser destinada a campañas } \\
\text { femeninas. } \\
\text { Límite de gastos de las campañas } \\
\text { electorales. }\end{array}$ \\
\hline $\begin{array}{l}\text { Tiempo de TV } \\
\text { (HGPE) }\end{array}$ & $\begin{array}{l}\text { La campaña oficial en la televisión y } \\
\text { en la radio tempo duraba } 45 \text { días. } \\
\text { La distribución del tiempo sigue los } \\
\text { criterios: el } 90 \% \text { del total del tiempo } \\
\text { disponible dividido de acuerdo con } \\
\text { la votación anterior de los partidos } \\
\text { para la Cámara y el } 10 \% \text { restante } \\
\text { distribuido igualitariamente } \\
\text { entre todos los partidos con } \\
\text { representación en la Cámara de los } \\
\text { Diputados. }\end{array}$ & $\begin{array}{l}\text { La campaña oficial en la televisión } \\
\text { y en la radio es de } 35 \text { días. } \\
\text { La distribución del tiempo no } \\
\text { fue alterada: el } 90 \% \text { del total del } \\
\text { tiempo disponible dividido de } \\
\text { acuerdo con la votación anterior } \\
\text { de los partidos para la Cámara de } \\
\text { los Diputados, y el } 10 \% \text { restante } \\
\text { dividido igualitariamente. Sin } \\
\text { embargo, ya no se requiere que la } \\
\text { representación del partido en la } \\
\text { Cámara tenga derecho a HGPE en } \\
\text { la distribución equitativa del } 10 \% \text {. }\end{array}$ \\
\hline $\begin{array}{l}\text { Tiempo de } \\
\text { Campaña }\end{array}$ & $\begin{array}{l}\text { La campaña oficial era, en media, de } \\
90 \text { días. }\end{array}$ & La campaña oficial duró 45 días. \\
\hline
\end{tabular}

Fuente: Elaboración propia, datos TSE.

Este dinero público tiene como destino las Ejecutivas Nacionales de los partidos, que, a su vez, no cuentan por ley con criterios específicos para la distribución 
interna de los recursos. Conforme Schaefer (2018) y Campos (2009), los valores tienden a ser destinados para los candidatos más competitivos y las comisiones estaduales y municipales con mayor relevancia en la disputa intrapartidista. Otra alteración en el uso de la financiación pública ha sido la obligación de gastar un 30\% de este recurso en campañas de candidatas mujeres. Es importante resaltar que 34 de los 35 partidos registrados por el TSE consiguieron recursos del FEFC. El valor total, R\$1.716.209.431,00, fue concedido por el Tesoro Nacional el 1 de junio de 2018. MDB, PT y PSDB fueron los partidos que recibieron más: poco más de 230 millones de reales para el MDB, 212,2 millones para el PT y 185,8 millones para el PSDB. Anteriormente, todos los partidos recibían una parte del Fondo Partidista para mantener la estructura partidista y el tiempo de HGPE en radio y televisión era calculado según el número de escaños en la Cámara. La tabla 4 resume los cambios ocurridos en las leyes de financiación electoral.

\section{LA RUPTURA DEL PATRÓN DE FINANCIACIÓN ELECTORAL}

La prohibición de las donaciones de empresas produce un impacto visible en las elecciones de 2018, tal y como muestra el gráfico 5. Hay un aumento proporcional de los valores originarios de fondos públicos, personas físicas y recursos propios. El aumento de recursos públicos para los partidos y para los candidatos es consecuencia de la creación del FEFC (67,29\% del total).

Tabla 5. Origen de las donaciones de las campañas presidenciales (2018)

\begin{tabular}{lc}
\hline \multicolumn{1}{c}{ Año/Tipo de recurso } & $\mathbf{2 0 1 8}$ \\
\hline Dinero público & 67,29 \\
Personas físicas & 7,01 \\
Recursos propios & 25,70 \\
Pessoas Jurídicas & 0,00 \\
\hline
\end{tabular}

Fuente: TSE.

En términos de los destinatarios de los recursos, como puede observarse en la tabla 6, a diferencia de las elecciones de 2010 y 2014, en 2018, los valores se distribuyen más entre los candidatos. Los valores se presentan en porcentajes, considerando el total recolectado por todos los candidatos en la elección. Fernando Haddad, del PT; Geraldo Alckmin, del PSDB, y, Ciro Gomes, del PDT, fueron los candidatos 
con más recursos públicos disponibles. Henrique Meirelles, del MDB, financió su propia campaña electoral. En valores nominales, estas cuatro campañas (las más caras) recaudaron, respectivamente: 55 millones de reales ${ }^{16}, 54$ millones, 24 millones y 57 millones. Meireles, exejecutivo del Banco Lazard Americas, expresidente del Banco Central durante los gobiernos de Lula (2003-2010) y ministro de Hacienda en el gobierno Temer (2016-2018), corrió con todos los gastos de su campaña (TSE, 2018). Este fenómeno del millonario que se autofinancia también se repite con otro candidato: João Amoedo, millonario del mercado financiero y candidato de un partido recién fundado, Ilamado Partido Novo. El 25\% de todo el valor recaudado por las campañas presidenciales provenía del bolsillo del propio Meirelles.

Tabla 6. Recaudación de los candidatos en 2018 (\%)

\begin{tabular}{lccc}
\hline Partido & Dinero público & Persona física & $\begin{array}{c}\text { Recursos propios de } \\
\text { candidato }\end{array}$ \\
\hline DC & 0,42 & 0,00 & 0,00 \\
MDB & 0,00 & 0,00 & 25,65 \\
NOVO & 0,00 & 2,08 & 0,04 \\
PATRI & 0,00 & 0,00 & 0,00 \\
PDT & 10,49 & 0,40 & 0,00 \\
PODE & 1,48 & 0,96 & 0,00 \\
PPL & 0,20 & 0,00 & 0,00 \\
PSDB & 24,18 & 0,13 & 0,00 \\
PSL & 0,27 & 1,69 & 0,00 \\
PSOL & 2,70 & 0,09 & 0,00 \\
PSTU & 0,24 & 0,01 & 0,00 \\
PT & 24,14 & 1,02 & 0,00 \\
REDE & 3,11 & 0,57 & 0,00 \\
\hline
\end{tabular}

Fuente: TSE

A continuación, se comprueba si existe correlación entre el dinero total recaudado por las campañas presidenciales y el total de votos recibidos por los candidatos en la primera vuelta de las elecciones presidenciales de 2010, 2014 y 2018 . Tal y como refleja el gráfico 2 existe una correlación casi perfecta entre votantes (eje

1613 millones, 12 millones, 6 millones y 14 millones de dólares, respectivamente. 
Y) y dinero (eje X) en las elecciones de $2010\left(r^{2}=0,950\right)$ y $2014\left(r^{2}=0,918\right)$, pero es insignificante en $2018\left(r^{2}=0,041\right)$. El candidato vencedor, Jair Bolsonaro, invirtió poco dinero en su campaña. Los candidatos con campañas millonarias lograron pocos votos, como Henrique Meirelles y João Amoedo. Por tanto, en 2018 hay un cambio profundo en el patrón.

\section{Gráfico 2. Correlación entre dinero recaudado y voto para presidente}

$(2010,2014,2018)$

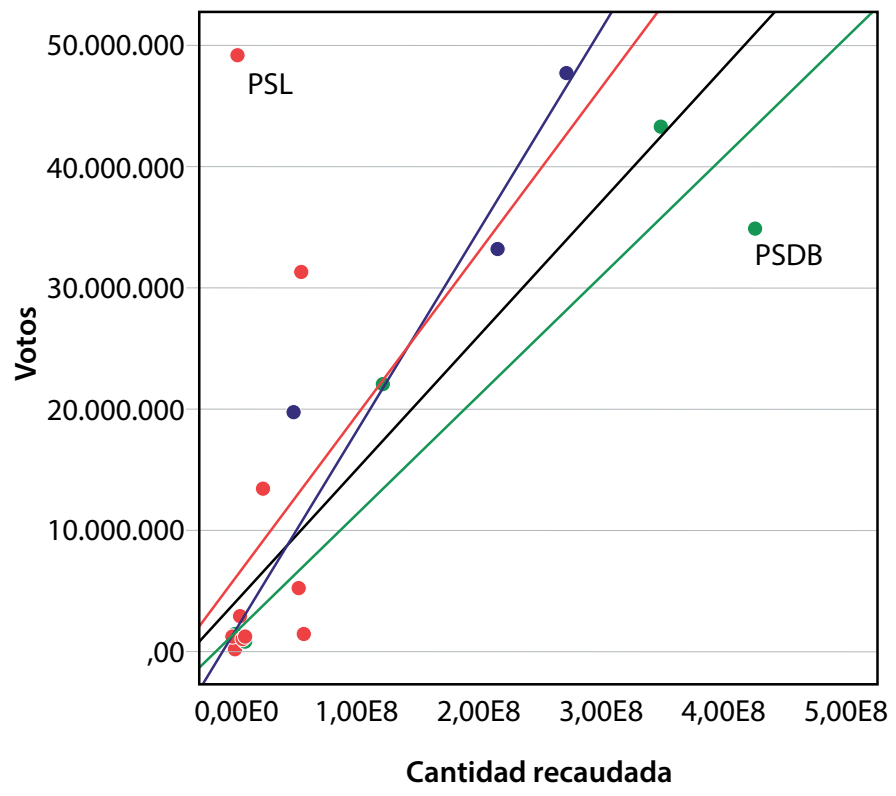

Año Elecciones

2010

2014

2018

$\backslash 2010$

$\backslash 2014$

$\backslash 2018$

$\mathrm{R}^{2}$ Linear $=0,561$

2010: $R^{2}$ Linear $=0,950$

2014: $R^{2}$ Linear $=0,918$

2018: $R^{2}$ Linear $=0,041$

Fuente: TSE.

\section{EL ESCENARIO DE LAS ELECCIONES DE 2018: DESAFECCIÓN POLÍTICA, REDES SOCIALES Y FAKE NEWS}

Varios factores deben ser tenidos en consideración para comprender las elecciones de 2018. Conforme ya han apuntado algunos especialistas, se trata de una elección crítica (Lavareda, 2018) dado que la campaña tiene lugar en un contexto de fuerte crisis económica, polarización ideológica y emergencia de una tercera vía consistente (Key, 1955; Schmitt et al., 2016; Onnudottir et al., 2016). Tales factores se alían con otros. Primero, los líderes de los dos principales partidos que centralizan la disputa presidencial desde 1994 y que gobernaron el país durante 22 
años fueron retirados de la elección por la Operación Lava Jato: Lula da Silva (PT) y Aécio Neves (PSDB). Segundo, el candidato Jair Bolsonaro sufrió durante la campaña un atentado. Tercero, el papel tan relevante de Internet, especialmente, de las redes sociales (Brito et al., 2018). Además de los cambios tan significativos en la legislación sobre financiación electoral, conforme se apuntó anteriormente.

Con relación al electorado, los líderes políticos y los partidos tradicionales fueron altamente rechazados y la desconfianza contaminó todas las instituciones del país, impactando fuertemente en el comportamiento del elector brasileño. El Instituto de Sondeos y Encuestas Data Folha reveló que únicamente el 5\% de los brasileños confiaba en el Poder Ejecutivo, el $3 \%$ en el Legislativo y el $2 \%$ en los partidos. El rechazo a los candidatos durante la campaña también fue alto y sintetizó un sentimiento generalizado. En las elecciones mayoritarias, generalmente, el candidato menos rechazado suele ser el ganador. Sin embargo, en las elecciones de 2018 los sondeos mostraban que pasarían a la segunda vuelta los candidatos más rechazados. Así, en la segunda vuelta la elección dependió del candidato que menos rechazo causaba. Jair Bolsonaro alcanzó la presidencia por causar menos rechazo que el candidato del PT, sumado a su discurso anticorrupción y sus posicionamientos sobre seguridad pública.

Aunque Bolsonaro ya contase con una trayectoria política significativa, más de 20 años como parlamentario, el contexto histórico y político que atravesaba el país le dio la oportunidad perfecta para que su candidatura y su partido fuesen una alternativa novedosa para una amplia parte de la sociedad. Bolsonaro dio voz a pautas de la extrema derecha, que se distancian fuertemente de las políticas y medidas propuestas por el Gobierno del PT, como las políticas de identidad, reconocimiento y redistribución de la renta.

De hecho, los brasileños han apostado por el proyecto y en la imagen que Jair Bolsonaro ha construido durante su campaña. Por primera vez, Brasil ha elegido, democráticamente, una lista encabezada por militares para el cargo de presidente y vicepresidente. El uso de las estrategias personalistas por los partidos políticos es un fenómeno endémico en las elecciones presidenciales. El contexto brasileño se ha caracterizado por una elevada volatilidad electoral y una dependencia de los partidos de las grandes personalidades como reclamo electoral en los medios de comunicación. Por otro lado, el tiempo de HGPE que le correspondía al PSL era de apenas 9 segundos, mientras que los candidatos del PSDB, del PT y del MDB acaparaban cerca del $85 \%$. No obstante, el atentado sufrido por Jair Bolsonaro a principios de septiembre le permitió alcanzar una amplia visibilidad tanto en las noticias como en las redes sociales. Por tanto, aunque el tiempo de televisión, a priori, era mínimo, dificultando su contacto con el electorado, fue compensado con sus apariciones diarias en las noticias sobre su estado de salud. 
Figura 3. Mapa de interacciones sobre el ataque a Bolsonaro

\section{$40,5 \%$}

Habla del ataque como una "puñalada falsa" y se burlan de las críticas de la derecha a la falta de empatía de la izquierda. .

$12,7 \%$

Demuestra apoyo a Bolsonaro, queriendo su recuperación y critica a la izquierda por sus cargos.

$9,8 \%$

Mensajes de solidaridad de candidatos como Ciro Gomes y Haddad, pero recuerda la falta de empatía de Bolsonaro en eventos similares.

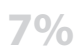

Critica a la izquierda por su desconfianza en la autenticidad del ataque. Muestra solidaridad al candidato.

Fuente: Twitter; Elaboración FGV (2018).

El atentado tuvo como resultado la fuerte participación de los usuarios de Twitter. Se verificó que inmediatamente después del ataque, las menciones de su nombre ascendieron hasta 808.400 veces entre las $16 \mathrm{~h}$ y las $18 \mathrm{~h}$ del mismo día. A las $18 \mathrm{~h}$, cuatro de los diez términos más mencionados en Brasil hacían relación a lo sucedido: violencia (216.000 menciones), arma (123.000), Juiz de Fora (88.000) y puñalada (83.000). Mientras que los hashtags eran \#bolsonaropresidente17 $(0,6 \%)$, \#bolsonaro (0,5\%), \#urgente (0,5\%), \#elecciones2018 (0,4\%) y \#fuerzabolsonaro $(0,3 \%)$. Según las mediciones de la $\mathrm{FGV}^{17}$, este suceso tuvo la mayor repercusión inmediata en Twitter desde las elecciones de 2014.

Además de las modificaciones legales sobre financiación y el tiempo de campaña, la principal novedad de esta elección es la regulación de las publicaciones en las redes sociales. Se impone una ley que obliga a las aplicaciones y redes sociales a interrumpir aquellas publicaciones que promoviesen el discurso del odio y divulgasen informaciones falsas. Con esta acción el objetivo era impedir que perfiles falsos fuesen utilizados para atacar a los candidatos con difamaciones y fake news.

17 Según un análisis con 22.572 .583 posts relacionados con el debate sobre los cinco candidatos mejor posicionados para la presidencia (Jair Bolsonaro, Ciro Gomes, Geraldo Alckmin, Marina Silva y Fernando Haddad), durante el primer mes de campaña (del 16 de agosto al 16 de septiembre), Bolsonaro es el candidato más citado en Twitter, tanto por perfiles conservadores como progresistas, evidenciando la polarización de la elección. 
Las fake news son clickbaits utilizados en las campañas políticas, pero esto no es algo nuevo. Actualmente la diferencia es la velocidad de difusión del contenido en el ambiente online especialmente por el uso de las redes sociales (Delmazo y Valente, 2018). Los delitos cibernéticos han sido en Brasil un tema central ${ }^{18}$, puesto que es el país latino con mayor número de visitas diarias a las redes sociales y el país con mayor duración de las mismas cuando se compara con la media por región del resto del mundo. Nada menos que el 10\% del tiempo usado mundialmente en las redes sociales es de los brasileños, el segundo lugar en el ranking internacional. El porcentaje de fans de Facebook aumentó entre enero de 2013 y junio de 2014 un 179\%. En 2016, de acuerdo con los dados de Symantec, Brasil ocupaba el octavo país del mundo con más bots. Un consorcio que monitorea redes sociales a nivel mundial (Spamhaus, 2020), constató en mayo de 2017, 485.133 bots en Brasil, posicionado el país solamente por detrás de China, India, Rusia y África del Sur. La Junta de Análisis de Políticas Públicas de la FGV ha demostrado que, en 2018 , las cuentas automatizadas generaban hasta el $20 \%$ del debate en apoyo a los políticos en Twitter. Estos hallazgos supusieron un riesgo para la democracia y el proceso electoral de 2018, que culminó con la elección de Jair Bolsonaro. Desde las elecciones de 2014, los bots han sido responsables de debates en Twitter con una fuerte repercusión política. La automatización permite la masificación de las publicaciones y se ha convertido en un instrumento para la manipulación del debate virtual, especialmente durante los periodos de mayor relevancia política. El mundo virtual ha permitido, ahora a gran escala, la implementación de viejas prácticas como la difamación y la manipulación del debate público.

Durante la elección de 2018 las noticias falsas alcanzaron grandes proporciones al propagarse por las redes sociales. Las noticias falsas funcionaron tan bien porque los usuarios tienden a confiar en opiniones formadas y moldeadas por grupos influentes si dichos contenidos confirman su visión del mundo, sobre todo si se desconfía en las instituciones representativas como en Brasil. La encuesta realizada por IDEA BIG DATE durante la campaña destaca la importancia de las fake news para el elector de Bolsonaro -el 98,21\% de sus electores recibieron noticias falsas y el $89,77 \%$ las consideraba verídicas- (Pasquini, 2018).

Ya sea en función de las restricciones impuestas por la legislación para recaudar dinero o ya sea porque la desconfianza en los medios de comunicación tradicionales ha disminuido, las redes sociales han sido las grandes influenciadoras del resultado de las elecciones presidenciales (Fundación Getúlio Vargas-FGV, 2018). Las fake news fueron difundidas, sobre todo, por el Whatsapp dado que están cifradas y dificultan rastrear a los diseminadores. Utilizaban técnicas de psicométrica que permiten que los mensajes instantáneos se envíen según las características del

18 Dan Arnaudo (2017). 
receptor. Esta tecnología que supone un coste elevadísimo fue difundida y alcanzó su auge con la candidatura de Donald Trump en los Estados Unidos.

Las campañas político-electorales desean conocer a su elector para desarrollar discursos más persuasivos (Lavareda, 2009). Las redes sociales permiten, mediante sus herramientas, que las campanas de marketing, sean políticas o no, lleguen a diferentes segmentos de los usuarios. Al patrocinar contenidos en las redes es posible direccionarlos para determinados segmentos, mediante la categorización demográfica (edad, género y región) y de intereses de los usuarios. Por tanto, las organizaciones políticas y empresariales se benefician de los datos de los usuarios. Esta es una forma de potencializar la influencia de las campañas político-electorales, aumentando la capilaridad de la comunicación de los partidos y sus candidatos con el elector, a partir de sus características demográficas e intereses personales y políticos (FGV, 2017).

De acuerdo con el reportaje publicado en el periódico Folha de São Paulo, empresas que apoyaban a Jair Bolsonaro estarían pagando el envío de mensajes por WhatsApp para favorecer al candidato y perjudicar a su principal adversario, Haddad (PT). Tras esta denuncia de incumplimiento de la ley de financiación, el Ministerio Público Electoral (MPE) declaró que investigaría si realmente las empresas privadas financiaron la campaña de Bolsonaro y el PSL. Al menos dos peticiones de investigación fueron registradas en la Procuraduría General Electoral (PGE). En otra investigación llevada a cabo por la Revista VEJA durante el periodo electoral, en agosto de 2018, identificaron la utilización de robots en Twitter para promover y mostrar una influencia mayor por parte de los electores de Bolsonaro. Durante el debate electoral televisado en el canal Band, algunos de los temas relacionados con Bolsonaro se convirtieron en Trending Topics del Twitter. Los bots publicaban frases repetidas e incluso en algunos casos llegaban a interactuar con usuarios que comentaban la aparición del candidato en la televisión.

Incluso cuando Bolsonaro no participaba en los debates, el candidato continuaba siendo el más citado en Twitter. El candidato fue varias veces líder en menciones en las redes sociales (Brito Cruz et al., 2018) ${ }^{19}$. La FGV analizó las referencias de las principales fake news en redes sociales como Twitter, Facebook y Youtube para medir el alcance que obtuvieron en cada plataforma y cual es la respuesta de las redes a estos contenidos. Las principales fake news giraban en torno al fraude en

19 Sobre las fuentes de los datos utilizados en este artículo: Además de la FGV, las fuentes de datos proceden de "Você na Mira» es un proyecto de InternetLab en colaboración con WhoTargets, con el objetivo de monitorizar la dirección de propagandas políticas en Facebook para brindar más transparencia a las estrategias de campaña. Esta herramienta funcionó como un plugin (también denominado como extensión) para recolectar datos sobre las publicaciones patrocinadas recibidas por los usuarios y conocer más sobre cómo fueron dirigidas, permitiendo conocer para que públicos los candidatos han dirigido sus diferentes contenidos. Ya el Laboratorio de la FGV acompañó las elecciones de 2018 y monitorizó las redes sociales. 
las urnas, el Kit Gay, el Libro de Haddad, la pedofilia y la patrona de Brasil, siempre direccionadas a desgastar al candidato Haddad y llegar al mayor número de personas.

En la recta final de la segunda vuelta, el WhatsApp se transformó en la pauta principal del debate sobre los candidatos presidenciales, en función de las denuncias realizadas por el periódico Folha de São Paulo vinculando los mensajes instantáneos y la financiación de empresarios. El 18 de octubre, las menciones al WhatsApp aumentaron vertiginosamente. Durante el último día de campaña fueron identificadas 1.212 cuentas automatizadas, que representaban el 0,3\% de los perfiles totales del mapa de interacciones. Estas generaron 80.035 interacciones ilegítimas, lo que equivale al $4,6 \%$ del total.

Gráfico 3. Evolución de las menciones sobre Whatsapp en Twitter (del 01 al 21 de octubre de 2018)

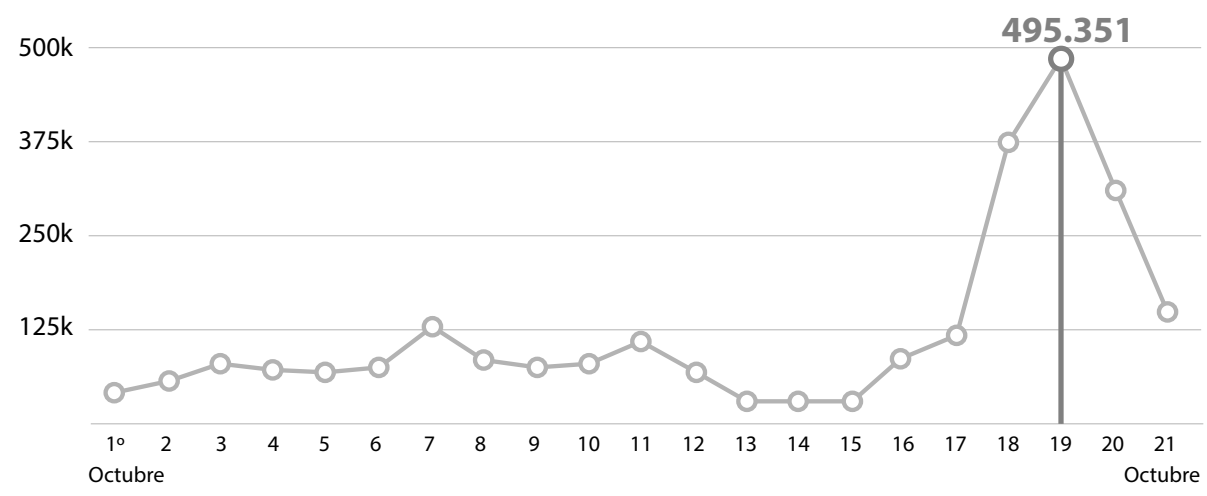

Fuente: Twitter; Elaboración: FGV (2018).

Por tanto, es importante observar que aunque los costes de campaña se hayan reducido oficialmente, hay fuertes indicios de que la campaña electoral de 2018 migró el gasto de las producciones televisivas a las redes sociales, lo que dificulta el control por parte del Tribunal Electoral. Los estudios realizados por la FGV confirman que los robots interactuaban en los debates electorales y que la presencia de nuevas tecnologías representa un cambio importante en la manera de hacer campaña: lanzar mensajes falsos y verdaderos en las redes sociales y en las aplicaciones de mensajería instantánea. Esta tendencia dificulta el control de los gastos, pues es fácil no declararlos, por lo que el TSE tendrá que evitar estos problemas y luchar contra los perfiles automatizados. La elevada desconfianza en la política y en las instituciones representativas tornaron la elección de 2018 la más polarizada de su 
historia y todavía se desconoce el coste financiero del uso de estas nuevas estrategias de marketing que burlan la legislación electoral.

\section{CONCLUSIÓN}

Los cambios en las reglas de financiación y en la campaña electoral sugieren algunas reflexiones tanto sobre sus efectos en las organizaciones partidistas, como en las nuevas formas en que los candidatos se relacionan con el elector.

Desde el punto de vista de la rendición de cuentas oficial de los candidatos presidenciales del TSE, con la prohibición de la financiación empresarial, las redes tradicionales de financiación fueron prohibidas y el poder financiero de las empresas que invertían en campaña no fue central en la de 2018. Las empresas relacionadas con los escándalos de corrupción se abstuvieron de donar para la campaña presidencial. Sin embargo, la prohibición de la financiación empresarial no ha impedido que los candidatos millonarios invirtiesen en sus propias campañas. Esta elección ha contado con verdaderos emprendedores políticos con éxito electoral en las elecciones al Legislativo y en los gobiernos estaduales. La disputa presidencial también ha contado con estos emprendedores, pero sus partidos no contaban con apoyos financieros. Por otro lado, aunque las empresas ya no pueden financiar, los empresarios y sus grupos familiares han incrementado sus donaciones como persona física.

A su vez, la financiación pública ha aumentado considerablemente, pero tal y como hemos evidenciado no ha contribuido a campañas victoriosas. Los candidatos a la presidencia vinculados a los partidos tradicionales brasileños y, por tanto, con mayor financiación estatal y tiempo gratuito en televisión, fueron derrotados. También hay que destacar que las nuevas formas de financiación sumergida se han intensificado. Algunos grupos religiosos han logrado esquivar las restricciones legales de financiación religioso, utilizando las donaciones de los fieles para financiar a los candidatos con mandatos proporcionales. La elección de 2018 sugiere que existe una nueva forma de financiación ilegal con la introducción masiva de nuevas formas de comunicación, que dificultan el rastreo y el control.

EI TSE está investigando actualmente la práctica de envíos masivos de mensajes en redes sociales financiados por empresas, consideradas ilegales en las elecciones de 2018. ataques cibernéticos y perfiles falsos para influir en las elecciones de 2018. Al momento de escribir este artículo, no hay una decisión sobre el caso (Boldrine y Campos Melo, 2019; Tribunal Superior Eleitoral, 2019a; 2019b).

El dinero ha sido un elemento clave para la campaña, tanto el legal como el ilegal que ha escapado al control del TSE. Según los datos oficiales sobre campañas presidenciales, el vencedor no fue el candidato que declaró más gastos y, además, su partido era insignificante. El caso brasileño demuestra que prohibir las donaciones empresariales y aumentar la financiación pública no son iniciativas suficientes 
para garantizar una competición equilibrada y transparente. Brasil está experimentando transformaciones y afrontando desafíos debido a las nuevas fuentes de financiación y al papel que están desempeñando las nuevas tecnologías de comunicación, como las redes sociales, con el elector. Ante esta crisis de representación, los cambios suponen oportunidades para el ascenso de líderes antipolíticos, populistas y de extrema derecha.

\section{REFERENCIAS}

Boldrine. A.; Campos Melo, P. (2019). TSE determina que WhatsApp informe se empresas fizeram disparos em massa nas eleições, Folha de São Paulo. https: //www1.folha. uol.com.br/poder/2019/11/tse-determina-que-whatsapp-diga-se-empresas-fizeramdisparos-em-massa-na-eleicao.shtml

Brito Cruz, F.; Massaro, H.; y Lago, L. (2018). O impulsionamento de conteúdo de pré-candidaturas na pré-campanha de 2018. Você na Mira Relatório 1\#. InternetLab. Recuperado de https: //www.internetlab.org.br/wp-content/uploads/2018/08/Relat\%c3\%b3rio-1Voc\%c3\%aa-na-Mira.pdf

Campos, M. M. (2009). Democracia, partidos e eleições: os custos do sistema partidário-eleitoral no Brasil. (Tesis de doctorado en Ciencia Política) Universidade Federal de Minas Gerais.

Carazza, B. (2018). Dinheiro, eleições e poder: as engrenagens do sistema político brasileiro. Companhia das Letras.

Dan Arnaudo (2017). Computational Propaganda in Brazil: Social Bots during Elections. En Samuel Woolley y Philip N. Howard, Eds. Working Paper 2017.8. Project on Computational Propaganda. comprop.oii.ox.ac.uk. <http: //comprop.oii.ox.ac.uk/>. 39 pp.

Delmazo, C. y Valente, J. C. L. (2018). Fake News nas redes sociais online: propagação e reações à desinformação em busca de cliques. Media \& Jornalismo, 18(32). pp. 155-169.

FGV (2017). A study on illegitimate interferences with the public debate on the web, risk to the democracy and the 2018 elections. Diretoria de Análise de Políticas Públicas.

FGV (2018) Redes Sociais nas Eleições 2018. Policy Paper 1. \#Observa2018. Sala de Democracia Digital. Diretoria de Análise de Políticas Públicas.

Fleischer, D. (1997). Sistema Partidário Brasileiro: 1945-1997. Política Comparada, 1(2), 227-257.

Gohn, M. G. (2017). Manifestações e protestos no Brasil: correntes e contracorrentes. Cortez Editora.

Goulart, J. (2018). Grandes empresários evitam financiar presidenciáveis, Folha de São Paulo. https: //www1.folha.uol.com.br/poder/2018/09/grandes-empresarios-evitam-financiar-presidenciaveis.shtml.

Hunter, W. (2007). Corrupção no Partido dos Trabalhadores. O dilema do «sistema». En J. Nicolau y T. Power, Instituições representativas no Brasil. Balanço e reforma (pp. 155167). Ed. UFMG. IUPERJ/UCAM.

Key V. O., Jr. (1955). A Theory of Critical Elections. Journal of Politics, 17, 3-18. 
Kirchheimer, O. (1966). The Transformation of the Western European Party Systems. En J. LaPalombara, y M. Weiner, Political Parties and political Development (pp. 177-176). Princeton University Press.

Krause, S. (2010). The need for balance in party financing in Brazil. En A. Butler (ed.), Paying for Politics: Party Funding and Political Change in South Africa and the Global South (pp. 116-136). Jacana Media.

Krause, S., Rebello, M. MI. y Da Silva, Jr. G. (2015). O perfil do financiamento dos partidos brasileiros (2006-2012): o que as tipologias dizem? Revista Brasileira de Ciência Política, 16, 247-272. https: //doi.org/10.1590/0103-335220151610.

Laakso, M. y Taagepera, R. (1979). Effective Number of Parties. A Measure with Application to Western Europe. Comparative Political Studies, 12(1), 3-27. https: //doi. org/10.1177/001041407901200101.

Lavareda, A. (2009). Emoções Ocultas e Estratégias Eleitorais. Ed. Objetiva.

Lavareda, A. (2018). Eleição crítica e troca de guarda, Veja. https: //veja.abril.com.br/blog/ noblat/eleicao-critica-e-troca-de-guarda/.

Pasquini, P. (2018). Estudo diz que 90\%dos eleitores de Bolsonaro acreditam em fake News, Valor. https: //valor.globo.com/politica/noticia/2018/11/02/estudo-diz-que-90-doseleitores-de-bolsonaro-acreditaram-em-fake-news.ghtml

Rebello, A.; Martins L. (2018). Empresários ampliam doações e assumem lugar de suas empresas nas eleições. https: //noticias.uol.com.br/politica/eleicoes/2018/noticias/2018/09/14/ empresarios-doacoes-de-campanha-eleicoes-2018.htm.

Samuels, D. (2001). Money, Elections and Democracy in Brazil. Latin America Politics and Society, 23, 27-48. https: //doi.org/10.1111/j.1548-2456.2001.tb00398.x.

Schaefer, B. (2018). As Lógicas de Distribuição do Fundo Partidário: centralização e nacionalização dos partidos brasileiros (2011-2015). Dissertação apresentada no Programa de Pós-Graduação em Ciência Política da UFRGS.

Silva, É. A. B. (2017). Corrupção e opinião pública: o escândalo da Lava Jato no Governo Dilma Rousseff. (Tesis de doctorado en Ciencia Política). Universidade Federal de Minas Gerais.

Onnudottir, E.; Schmitt, H.; y Haroarson, O. (2016). Critical Election in the Wake of an Economic and Political Crisis: Realignment of Icelandic Party Voters? Scandinavian Political Studies, 40, 157-181. https: //doi.org/10.1111/1467-9477.12085.

Spamhaus (2020) The top 10 worst botnet countries, 2017. The SpamHouse Projetc. https: //www.spamhaus.org/statistics/botnet-cc/.

Souza, M. C. (1976). Estado e Partidos Políticos no Brasil (1930-1962). Alfa Ômega.

Telles, H. S. (2015). Corrupção, Legitimidade Democrática e Protestos: o Boom da Direita na Política Nacional? Interesse Nacional, 8, 28-46.

Telles, H. S. (2016). A crise política na ausência de política. Em Debate (Belo Horizonte), v. 8, p. 17-26.

TSE (2016). Novas Regras Eleitorais: mudanças no cálculo do tempo do horário eleitoral no rádio e na TV. http: //www.tse.jus.br/imprensa/noticias-tse/2016/Maio/ novas-regras-eleitorais-mudancas-no-calculo-do-tempo-do-horario-no-radio-e-na-tv.

TSE (2019a). Corregedor determina que WhatsApp informe se números identificados disparam mensagens em massa em 2018. http: //www.tse.jus.br/imprensa/noticias-tse/2019/Novembro/corregedor-determina-que-whatsapp-informe-se-numeros-identificados-dispararam-mensagens-em-massa-em-2018. 
TSE (2019b). Corregedor abre prazo para partes da ação que investiga disparos em massa pelo WhatsApp se manifeste. http://www.tse.jus.br/imprensa/noticias-tse/2019/Dezembro/ corregedor-abre-prazo-para-que-partes-de-acao-que-investiga-disparos-em-massapelo-whatsapp-se-manifestem. 
